SHORT TITLE: Spelling Greek derivations and inflections

Spelling of derivational and inflectional suffixes by Greek-speaking children with and without dyslexia

\author{
Vassiliki Diamanti, ${ }^{1} \dagger$ Nata Goulandris, ${ }^{1}$ Morag Stuart, ${ }^{2}$ Ruth Campbell ${ }^{1}$ \\ ${ }^{1}$ University College London, UK; ${ }^{2}$ Institute of Education, London, UK
}

Correspondence: Vassiliki Diamanti

Timotheou 82-86, 16231 Vyronas, Greece

Tel: +30 6979771660

e-mail: vassiliki.diamanti@gmail.com

\begin{abstract}
Author notes
Vassiliki Diamanti is now with the Department of Primary Education, University of Crete, Greece.

The study was supported by the Human Communication Science Departmental Scholarship of University College London, the Leon Lemos Foundation Scholarship, and the Sir Richard Stapley Educational Trust Fund.

We thank Athanassios Protopapas for the mixed model analyses and for helpful comments on the manuscript.
\end{abstract}




\begin{abstract}
We investigated the spelling of derivational and inflectional suffixes by 10-13year-old Greek children. Twenty children with dyslexia (DYS), 20 spelling-levelmatched (SA) and 20 age-matched (CA) children spelled adjectives, nouns, and verbs in dictated word pairs and sentences. Children spelled nouns and verbs more accurately than adjectives and inflections more accurately than derivational suffixes. DYS children performed worse than $\mathrm{CA}$ in all cases and worse than SA in verb inflections, but similar to SA in all the remaining cases, consistent with a delayed rather than deviant performance pattern. Qualitative analysis showed that uncommon vowel graphemes were often replaced by more common patterns. Children with dyslexia may have weaknesses in grasping morphological information and/or in applying this knowledge to spell word suffixes.
\end{abstract}




\section{Spelling of derivational and inflectional suffixes by Greek-speaking children with and without dyslexia}

Spelling development is a protracted and complex process that involves the integrated processing of phonological, orthographic, grammatical and semantic knowledge (Bryant, Nunes \& Aidinis, 1999; Ehri, 1997). Phonological processing is a basic component involved in the acquisition of skills that are necessary for the successful development of spelling ability (Wagner \& Torgesen, 1987; Wagner, 1988; Wagner, Torgesen \& Laughton, Simmons \& Rashotte, 1993). Research in orthographies more transparent than English has confirmed the universal importance of phonological awareness for learning to spell (e.g., Czech, Caravolas, 2004; German, Landerl \& Wimmer, 2008; Norwegian and Swedish, Furnes \& Samuelsson, 2010; and Greek, Aidinis \& Nunes, 2001; Mouzaki, Protopapas, \& Tsantoula, 2008; Nikolopoulos, Goulandris, Hulme, \& Snowling, 2006; Porpodas, 1990, 1992).

However, in many alphabetic languages learning to spell largely depends on another fundamental resource for the acquisition of orthographic competency, namely morphology, as the spelling patterns that represent morphemes cannot be derived from phonology alone. The morphological constituency of words includes grammatical inflection, derivation of related parts of speech, and compounding (Ralli, 2005). In this study we investigated spelling ability focusing on inflectional and derivational morphemes, which are of theoretical importance and present particular challenges to developing Greek spellers.

\section{Greek Morphology}

Spelling in Greek is governed by an extensive system of morphological word 
ending rules that vary according to part of speech (Papanastasiou, 2008). Greek nouns belong to a variety of declensions, i.e., the system of endings that serve to indicate number (singular, plural), case (nominative, genitive, accusative, vocative) and gender (masculine, feminine, or neuter). Each noun may have up to 7 different forms, depending on declension, each with its own suffix and associated spelling. Discounting variants and special cases, there are roughly 21 noun declension classes (Holton, Mackridge, \& Philippaki-Warburton, 2004).

Nouns undergo changes to form new words by morphological processes. One way of forming derivatives is the addition of a suffix to the stem (derivational suffixation;

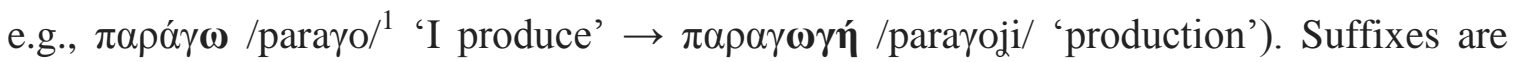
used to form diminutives (which express small size, affection, familiarity, or

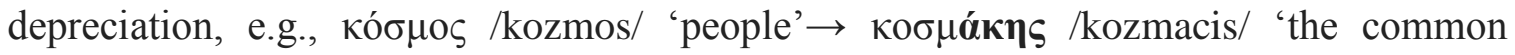

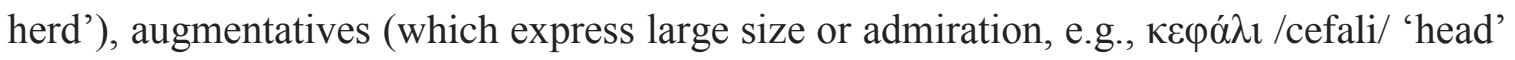

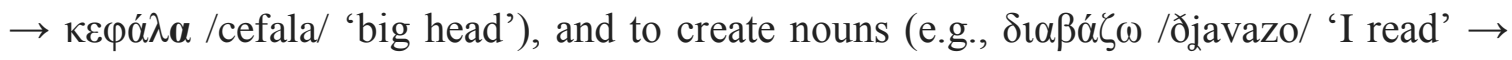
$\delta i \alpha ́ \beta \alpha \sigma \mu \alpha$ /ðjavazma/ 'reading').

In the same manner as nouns, adjectives are classified by gender into masculine, feminine and neuter, can be declined, and agree with the nouns they modify in number, gender and case. Each adjective may thus have up to 15 different forms, depending on declension, each with its own suffix and associated spelling. Discounting variants and special cases, there are roughly 12 adjective declension classes (Holton et al., 2004). In

\footnotetext{
${ }^{1}$ Broad phonetic transcriptions are provided using the International Phonetic Alphabet.
} 
addition, a number of derivational suffixes are used to create adjectives ( $\sigma 0 \zeta \eta \tau \omega ́$ /sizito/ 'I discuss' $\rightarrow \sigma \nu \zeta \eta \tau \eta ́ \sigma ı \mu \varsigma /$ sizitisimos/ 'debatable') or change the meaning of existing

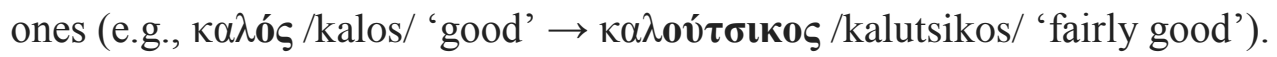

Verbs are generally acknowledged as the most complex part of the Greek morphological system, as they are inflected for person, number, tense, voice, and aspect (Holton et al., 2004). For this reason, Greek verbs exhibit a great variety of forms. Each verb may have as many as 29 different forms in the active voice plus 26 in the passive voice. There are 3 major conjugation classes as well as some variants and special cases.

It is necessary to make a distinction between the stem and the endings of verbs since they carry different morphological information. According to Ralli (2003) both the stem and the inflectional suffix could have a simple or complex morphological form. A morphologically complex stem could be derived or compound. The inflection could comprise up to three components: a) a mark indicating the person and number, b) a mark indicating the tense, and c) a mark indicating the aspect. Aspect is a grammatical category that refers to the finiteness of the verb, that is, "whether the action is presented as completed (perfective) or as progressive or repeated (imperfective)" (Holton et al., 2004, p. 505). Greek verbs fall into categories according to their regularity: Regular verbs fit into recognizable patterns in the way they construct their perfective stems. Verbs that form their perfective stem in ways that do not conform to these patterns or present irregularities in the formation of other form(s), e.g., the imperative, are classified as irregular verbs.

Explicit teaching of inflections begins very early in the educational system (as early as Grade 1 for the simplest classes) whereas explicit teaching of derivations is not 
initiated before Grade 2 (mainly with verb derivations). Instruction on both inflections and derivations continues throughout elementary education.

Stems, derivational and inflectional suffixes of Greek words include-in most cases - a vowel, represented by a particular grapheme. However, most vowels can be spelled with more than one grapheme. Specifically, /e/ can be represented either by $\varepsilon$ or $\alpha 1, / \mathrm{o} /$ can be spelled as o or $\omega$, and /i/ has six alternative spellings: $1, \eta, v, \varepsilon 1$, ol, v1. Therefore, when children spell the vowels included in the suffixes, they are faced with the task of deciding between alternative spelling representations. In other words, the orthographic consequences of morphology in Greek spelling concern vowels, almost exclusively, as the spelling of consonants is not affected by inflectional or derivational suffixation. Therefore, to study morphological spelling in Greek it is necessary to examine vowel spelling accuracy.

\section{Morphology in Spelling Development and Dyslexia}

An increasing number of studies have shown interest in the alternative spelling patterns that represent a phoneme and whether children adopt mostly one specific spelling at the beginning of learning to spell, and whether there is a differentiation at later stages of spelling development with respect to morphology. Evidence from Portuguese (Nunes Carraher, 1985; Nunes, 1992; cited in Bryant, Nunes, \& Aidinis, 1999) showed that at first there is a remarkable preference for one of the spelling choices, but through children's exposure to reading and writing the use of alternative spellings increases. Data from more than 200 Greek children 7-10 years old (Bryant, Nunes, \& Aidinis, 1999) has revealed a similar pattern. Beginning spellers tend to prefer one spelling of a sound even when there are clear alternatives. The use of alternative spellings emerges as children 
grow older.

Mastery of spelling skills in many orthographies also depends on morphological awareness (Caravolas, 2004; Landerl \& Reitsma, 2005; Levin, Ravid \& Rapaport, 2001), because word spelling partly depends on grammatical identity. Morphological awareness refers to the ability to represent and manipulate explicitly the morphological regularities that relate word parts to word meanings (Kuo \& Anderson, 2006). Children's awareness of inflectional morphology is detected earlier than awareness of derivational morphology. Evidence from English and Greek has shown that the former is acquired in the first school years (Kuo \& Anderson, 2006; Diakogiorgi, Baris, \& Valmas, 2005), whereas the latter develops towards the fourth year (Anglin, 1993; Carlisle, 2000). Children's grasp of morphological rules and their implications for spelling suffixes appears progressively in later stages of spelling development (Bryant et al., 1999; Waters, Bruck \& MalusAbramovitz, 1988).

Morphological spelling strategies have been investigated at various ages in several languages. In English, beginning spellers write the suffixes of regular past tense verbs phonetically, but as they grow older they increasingly add the 'ed' spelling to their repertoire (Read, 1986; Treiman, 1993; Treiman, Cassar, \& Zukowski, 1994). Mastery of conventional spellings for morphemes also depends on morpho-syntactic awareness and occurs at the later spelling stages (Nunes, Bryant, \& Bindman, 1997). However, recent research has shown that children as young as 6 to 8 years old can be sensitive to root morphemes when they spell morphologically complex words (Deacon \& Bryant, 2006), as well as to suffixes when filling in the ending of such words (Deacon \& Bryant, 2005). Several studies in French have shown that typically developing children's spelling is 
influenced by the morphological structure of words, as they appear to spell derived words more accurately than nonderived ones (Casalis, Deacon, \& Pacton, 2011; Pacton, Fayol \& Perruchet, 2005; Sénéchal, Basque \& Leclaire, 2006). Other researchers have emphasized the use of morpho-syntactic knowledge for writing French nouns, adjectives and verbs (Alegria \& Mousty, 1996; Totereau, Thevenin, \& Fayol, 1997). In Spanish, studies have shown that children in Grades 1-3 make use of morphosyntactic knowledge in spelling more systematically in the case of verbs than of nouns. Correct spellings increased progressively at higher grades, as children begin to internalize and generalize morphological rules of spelling (Defior, Alegría, Titos, \& Martos, 2008; Titos, Defior, Alegría, \& Martos, 2003). In Greek, Diakogorgi, Baris, and Valmas (2005) presented evidence that children as young as 7 years old (end of first grade) make some use of morphological spelling strategies (along with phonological spelling strategies, which seem to prevail).

In English, the spelling of inflectional suffixes poses greater difficulties to children with dyslexia compared to typically developing children (Bryant, Nunes \& Bindman, 1997). The spelling of derivational suffixes is also difficult for children with dyslexia and for younger typically developing readers (Tsesmeli \& Seymour, 2006). In line with these findings, Egan and Tainturier (2011) found that 9-year-old children with dyslexia were significantly poorer than younger reading and spelling-age control children at spelling inflected verbs and stems presented in isolation. The authors argued in favor of a morphological spelling deficit in children with dyslexia. On the contrary, children with dyslexia and younger spelling-level-matched children appear to be able to use to some extent their knowledge of words' stems in the spelling of derived words (Bourassa, 
Treiman, \& Kessler, 2006; Bourassa \& Treiman, 2008), as well as their knowledge of legal letter patterns (Cassar, Treiman, Moats, Pollo, and Kessler, 2005).

In their review of studies on the spelling of morphemes by typically developing speakers of English and French, Pacton and Deacon (2008) have pointed out the need for studies on the use of morphology in spelling by children with dyslexia in other orthographies. Evidence from the Arabic orthography (Abu-Rabia \& Taha, 2004) showed that $5^{\text {th }}$ grade dyslexic readers have a similar spelling profile with younger typical readers, whereby most spelling errors were phonetic, but there were also spelling errors reflecting poor knowledge of morphological rules.

In Greek, children with dyslexia have great difficulties with morphological spelling. Protopapas, Fakou, Drakopoulou, Skaloumbakas, and Mouzaki (in press) classified the spelling errors of 542 Greek-speaking children from the general population and 44 children with dyslexia attending grades 3-4 and 7 into different categories. The most frequent spelling errors occurred in derivational suffixes, stress diacritics, inflectional suffixes and lexically determined stem vowels. The proportion of spelling errors was greater for derivational than inflectional morphemes. Children with dyslexia made more errors than same-age poor readers and younger reading-matched children, but the most frequent error types were the same as for children without dyslexia. It was proposed that children's spelling errors in derivational and inflectional morphemes could be attributable to their difficulty in internalizing the systematicity of the orthographic system, while their spelling errors in word roots could be attributable to their difficulty in representing the particularity of the system. Nikolopoulos, Goulandris, and Snowling (2003) also revealed morphology-based spelling difficulties in Greek. Twenty-eight 
children with dyslexia were found to have difficulties with spelling multi-letter inflectional morphemes, but not with single-letter morphemes, reflecting lack of knowledge about spelling patterns that are underpinned by morphology. Overall most of the reviewed research findings from different orthographies suggest the existence of a delay in the spelling development of children with dyslexia, as opposed to a spelling deviance.

\section{Rationale and aims of the present study}

So far evidence from studies in inconsistent and consistent orthographies has shown that morphological knowledge is essential for learning to spell word inflections. However, the investigation of the role of morphological information in spelling derivational suffixes in Greek is still in its infancy. Previous studies have offered important starting points but have not distinguished between derivational and inflectional morphemes (e.g., Nikolopoulos et al., 2003) or have not used materials specifically designed to address morphological spelling (Protopapas et al., in press). No previous study has examined a wide range of morphemes or considered potential differences between diverse parts of speech. The present study sought to contribute to our understanding of spelling difficulties related to different parts of Greek words (stem, derivational suffix, inflectional suffix) both in typical development and in the case of children with reading and spelling difficulties.

Verbs exhibit a much richer inflectional system, more complex and variable than that of nouns and adjectives, and carrying much more grammatical information. Therefore, from this point of view, we might expect knowledge of verb inflections to lag behind noun and adjective inflections. This prediction stands in contrast to an 
undifferentiated approach to morphological effects in spelling development that might predict uniform attainment of spelling patterns over parts of speech dependent on some nonspecific morphological development. Conversely, because nouns and adjectives share a common set of inflections, we might expect no differences in the spelling accuracy of inflectional suffixes between these two parts of speech, despite the fact that adjectives range over all three genders whereas each noun belongs to a single grammatical gender.

Different morphological components carry different types of information. So it is possible that stems, derivations, and inflections follow distinct developmental trajectories in accordance with the gradual attainment of metalinguistic awareness at different levels. From this point of view it is important to compare the spelling accuracy of different morphological components in materials specifically developed for this purpose. Furthermore, psycholinguistic considerations lead to the hypothesis that spelling of derivations may lag behind inflections because inflections apply over a much wider range of words and are therefore more common and more frequently encountered in reading. In contrast, derivations occur within more restricted sets of words and are therefore less familiar and less practiced.

However, there are many more derivational morphemes forming nouns and adjectives than verbs (about 30:1, according to the list in Papanastasiou, 2008, pp. 303317). Thus it is not possible to form fully balanced sets of all three parts of speech including all three morphological components. Therefore, to retain the ability to test both critical predictions mentioned above, we used two different spelling tests, one comparing nouns and adjectives, including both derivational and inflectional morphemes, and another comparing nouns and verbs, focusing on stems and inflections only. To our 
knowledge this is the first study that has compared directly the spelling of morphological components of Greek words belonging to three different parts of speech by children with dyslexia and same-age typically developing children attending late primary and early secondary school, as well as by younger typically developing spellers.

As noted, studies in Spanish, Portuguese and Greek have found that children tend to use a specific spelling pattern for each phoneme at the beginning stages of spelling development and only gradually begin to use alternative graphemes (Bryant et al., 1999; Nunes Carraher, 1985; Nunes, 1992; cited in Bryant, Nunes, \& Aidinis, 1999; Titos, Defior, Alegria, \& Martos, 2003). However, the particular graphemes used and their relative frequencies have not been considered in any detail. Therefore another goal of this study was to explore the qualitative differences between the spelling mistakes of Greek dyslexic and typically developing children. More specifically we wanted to establish whether different patterns of substitutions of the misspelled vowels are evident in children with dyslexia when compared to typically developing children, and whether patterns of substitutions change with spelling development. It was expected that children with dyslexia would use a preferred spelling pattern. Therefore, in their pattern of substitutions they would be similar to spelling-age controls, but different from chronological-age controls, who would use more than one spelling pattern to represent vowel phonemes. It was also expected that children with dyslexia and spelling-age controls would exhibit a specific pattern of substitutions of the misspelled vowels, whereby they would use the most high-contingency (most common) spelling patterns.

The research questions were as follows: Do children with dyslexia and typically developing younger and same-age children differ in their accuracy of spelling 
derivational and inflectional suffixes? In which morphological component (stem, derivation or inflection) do children make most spelling errors? In which part of speech (noun, adjective or verb) do children make more spelling errors? Are children with dyslexia delayed or deviant in the spelling of different morphological components and parts of speech? And, finally, which alternative spelling patterns/substitutions are used by children with dyslexia and typically developing children?

\section{Method}

\section{Participants}

The sample included 20 children with dyslexia, 10-13 years old, with verbal and non-verbal IQ within the normal range (above 85 ) and reading ability score at least 1.5 SD below the normative mean on a sight word efficiency test. Twenty same-age typically developing children were enrolled into the chronological-age-match (CA) group, and 20 younger children matched for spelling level to the children with dyslexia were enrolled into the spelling-age (SA) control group. Participants were selected from a larger sample of 73 children (24 diagnosed with dyslexia, 22 same-age typically-developing children and 27 younger typically-developing children) to fit the spelling-match criteria. Participants with a history of sensory deficits, behavioural or emotional difficulties or irregular school attendance were excluded from the sample. In order to avoid circularity with the experimental spelling measures, younger children were selected to form the SA group on the basis of graphemic accuracy on a graded spelling dictation task, to match the group mean of children with dyslexia. The chronological-age control group (CA) was formed to match the children with dyslexia on group means for age and IQ. A spellinglevel-match design was employed, because it can be very informative about the existence 
of a deficit versus a delay in the spelling development of children with dyslexia (Bourassa et al., 2006, 2008). The children with dyslexia and younger spelling-levelmatched children were also indistinguishable in word reading fluency, pseudoword reading accuracy, phoneme deletion of nonwords, rapid digit naming, short-term memory span, and phonological spelling (Table S3 in the Supplementary Materials). Participants were recruited from one public elementary school and two public secondary schools located in the central district of Thessaloniki, Greece. These schools cater to families from a variety of socio-economic and ethnic backgrounds. Parental permission for participation in the study was granted for all participants, who were native speakers of Greek.

\section{Materials}

Selection measures. Inclusion in the study and group membership was based on (a) the subtests of Block Design and Similarities of the Greek Wechsler Intelligence Scale-III for children (Georgas, Paraskevopoulos, Besevegis, \& Giannitsas, 1997), (b) a Greek sight word efficiency test in the form of a list of 104 words devised along the lines of TOWRE Sight Word Efficiency Test (Torgesen, Wagner, \& Rashotte, 1999), and (c) a graded spelling dictation task comprising 57 words of graded orthographic difficulty and decreasing frequency of occurrence. Details about these tasks are provided in the online Supplementary Materials accompanying this article.

Cognitive and additional literacy profile measures. To fully characterize the profiles of the participants in each group, a battery of tests was administered, assessing phonological short-term memory (digit span), rapid naming of digits, phoneme deletion of nonwords, and pseudoword reading. Details about these tasks and descriptive statistics 
of performance for each group are provided in the online Supplementary Materials.

Experimental measures. There were two spelling tasks, one testing nouns and adjectives, in word pairs, and another testing verbs and nouns, in sentences.

Word spelling. This task included 28 adjective-noun pairs (e.g., $\tau \varepsilon \lambda \varepsilon v \tau \alpha i ́ o \varsigma$

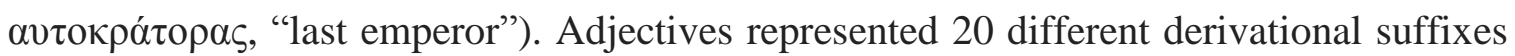
and nouns 16 different derivational suffixes. Word-pairs were either in singular or plural nominative, genitive, accusative or vocative cases with each word including a different derivational suffix (see the Supplementary Materials the list of suffixes and the complete test). The suffixes included the vowel phonemes /e/ (spelled with $\varepsilon, 78.0 \%$, or $\alpha$ l, 22.0\%), /o/ (spelled with $0,76.7 \%$, or $\omega, 23.3 \%$ ), and /i/ (spelled with $\eta, 39.1 \%, 1,34.0 \%$, v, $10.8 \%, \varepsilon 1,10.8 \%, \mathrm{ol}, 5.3 \%$, or vi, $0.02 \%$-grapheme frequencies from Protopapas \& Vlahou, 2009). The child was asked to write the word pairs dictated by the experimenter. One point was awarded for the correct spelling of each part of each word in the pair (stem, derivational suffix, inflection), for a total score per word pair ranging from 0 to 6 . Test reliability (Cronbach's $\alpha$ ) was .93 . In the analyses reported below, the six measures derived from each word pair $(2$ words $\times 3$ parts; each scored with 1 when correct) were considered individually.

Sentence spelling. This task comprised 18 sentences of 2-5 words including

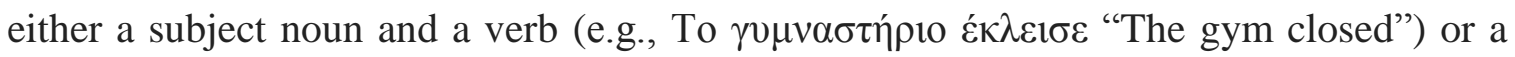

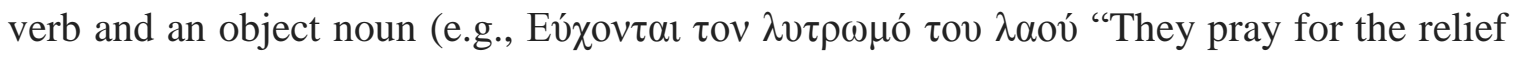
of the people"). Each verb (fifteen irregular and three regular) had a specific characteristic in the way it formed its active and/or passive stem. The majority of the verbs were in active voice with the exception of three, which were in passive voice. Items 
were distributed into singular and plural present and past tense (see Supplementary Materials for the complete test). Six verbs were in the first person, five in the second and seven in the third. Each noun was presented either in the nominative or the accusative singular form (two items were plural). Each target word (verb and noun) in each sentence was scored for correct stem and correct inflection (maximum score 4 for each word pair). Test reliability was .88. In the analyses reported below, the four measures derived from each sentence $(2$ target words $\times 2$ parts; each scored with 1 when correct) were considered individually.

\section{Procedure}

Children were tested in two group sessions of 30-40 minutes each a few days apart. In the first session they spelled the adjective-noun pairs. In the second session they spelled the sentences. Children's sight word and pseudoword reading, spelling, rapid digit naming, and digit span were assessed in sessions up to two week earlier; their verbal and nonverbal IQ scores were obtained eighteen months earlier.

\section{Results}

Accuracy data were analyzed using generalized linear mixed-effects models (Baayen, 2008), fitted with binomial distributions (Dixon, 2008) via a logit transformation (Jaeger, 2008), using package lme4 (Bates, Maechler, \& Bolker, 2012) in R (R Core Team, 2012). Models included crossed random effects of participants and words specified with maximal random structures (Barr, Levy, Scheepers, \& Tily, 2013). Conditions were deviation coded ( -0.5 vs. 0.5 in pairs of levels for each analysis) to result in estimation of main (i.e., average) rather than simple effects. Trial-level data were entered, analyzed as separate data points for each word part, related via the common item 
random effect. The main advantages of using this type of analysis over ANOVA are the simultaneous control of participant and item variance and the robustness to near-ceiling performance, in addition to increased power.

\section{Adjectives and nouns}

Table 1 (top) and Figure 1 (left) show the performance of each group on the spelling measure of adjectives and nouns.

The comparison between the two control groups showed that their spelling performance differed significantly across part of speech and morphological component, with younger control children (SA) performing significantly less accurately than older control children $(\mathrm{CA})$ (adjectives: $\hat{\beta}=-1.31, z=-3.33, p=.001$ for stem, $\hat{\beta}=-1.08, z$ $=-3.54, p<.001$ for derivation, $\hat{\beta}=-0.95, z=-2.02, p=.040$ for inflection; nouns: $\hat{\beta}=$ $-2.36, z=-4.52, p<.001$ for stem, $\hat{\beta}=-1.55, z=-3.47, p<.001$ for derivation, $\hat{\beta}=$ $-2.33, z=-4.37, p<.001$ for inflection).

Accordingly children with dyslexia (DYS) performed significantly worse than CA control children in spelling all three morphological components of both adjectives and nouns (adjectives: $\hat{\beta}=-0.93, z=-3.34, p=.001$ for stem, $\hat{\beta}=-1.59, z=-5.28, p<.001$ for derivation, $\hat{\beta}=-1.33, z=-2.65, p=.008$ for inflection; nouns: $\hat{\beta}=-2.69, z=-4.94$, $p<.001$ for stem, $\hat{\beta}=-1.77, z=-4.12, p<.001$ for derivation, $\hat{\beta}=-2.04, z=-4.37, p<$ .001 for inflection).

The comparison between children with dyslexia and younger typically developing spellers did not produce significant group differences across part of speech and morphological component (adjectives: $\hat{\beta}=-0.38, z=-1.37, p=.172$ for stem, $\hat{\beta}=.50, z$ 
$=1.93, p=.054$ for derivation, $\hat{\beta}=.38, z=.96, p=.339$ for inflection; nouns: $\hat{\beta}=.25, z$ $=.62, p=.535$ for stem, $\hat{\beta}=.27, z=.80, p=.424$ for derivation, $\hat{\beta}=.03, z=.09, p=$ .927 for inflection).

Considering the stem-inflection comparison, there was no significant difference between any groups or parts of speech, except for adjectives in the SA control group, in which stems were less accurately spelled than inflections $(\hat{\beta}=-1.58, z=-2.95, p=$ .003 ), and this difference was significantly greater than for the children with dyslexia (interaction of group by morphological component, $\hat{\beta}=-.93, z=-2.61, p=.009$ ).

In comparison between the three morphological components (stem-derivationinflection), spelling of derivations was less accurate than spelling of stems and inflections across group and part of speech (adjective derivation-stem comparison: $\hat{\beta}=2.41, z=$ 5.78, $p<.001$ for CA, $\hat{\beta}=2.74, z=7.39, p<.001$ for DYS, $\hat{\beta}=1.91, z=4.62, p<.001$ for $\mathrm{SA}$; noun derivation-stem comparison: $\hat{\beta}=2.60, z=3.55, p<.001$ for $\mathrm{CA}, \hat{\beta}=1.36$, $z=2.51, p=.012$ for DYS, $\hat{\beta}=1.37, z=2.64, p=.008$ for SA; adjective derivationinfection comparison: $\hat{\beta}=3.36, z=6.20, p<.001$ for $\mathrm{CA}, \hat{\beta}=3.71, z=7.39, p<.001$ for DYS, $\hat{\beta}=3.57, z=2.85, p=.004$ for $\mathrm{SA}$; noun derivation-inflection comparison: $\hat{\beta}=$ $2.26, z=2.63, p=.009$ for $\mathrm{CA}, \hat{\beta}=2.06, z=4.29, p<.001$ for DYS, $\hat{\beta}=1.60, z=2.85$, $p=.004$ for SA). In contrast, there was no significant difference between stems and inflections except for adjectives spelled by the SA group (adjective stem-inflection comparison: $\hat{\beta}=-1.03, z=-1.88, p=.060$ for $\mathrm{CA}, \hat{\beta}=-0.87, z=-1.60, p=.111$ for DYS, $\hat{\beta}=-1.58, z=-2.95, p=.003$ for $\mathrm{SA}$; noun stem-inflection comparison: $\hat{\beta}=$ $-0.56, z=-0.89, p=.376$ for CA, $\hat{\beta}=-0.55, z=-1.24, p=.217$ for DYS, $\hat{\beta}=-0.48, z=$ 
$-1.06, p=.291$ for SA).

For adjectives, the difference between derivations and inflections did not differ between groups (group by morphological component interaction: $\hat{\beta}=0.15, z=0.36, p=$ .717 CA-DYS, $\hat{\beta}=0.15, z=0.46, p=.644$ SA-DYS, $\hat{\beta}=0.21, z=0.47, p=.640$ CASA), but the difference between derivations and stems was greater for children with dyslexia than for CA controls $(\hat{\beta}=0.64, z=2.33, p=.020)$ and than for SA controls $(\hat{\beta}=$ $-0.90, z=-3.26, p=.001)$. For nouns, children with dyslexia did not differ from either CA or SA control children in the difference between derivations and inflections. The difference between derivations and stems was greater for CA controls than children with dyslexia $(\hat{\beta}=-1.38, z=-3.20, p=.001)$ and SA controls $(\hat{\beta}=-0.88, z=-2.06, p=$ $.040)$.

In comparison between the two parts of speech (adjectives vs. nouns) there was no significant difference in the spelling accuracy of stems and inflections by any group (CA: $\hat{\beta}=0.30, z=0.39, p=.693$ for inflection, $\hat{\beta}=1.58, z=1.83, p=.068$ for stem; DYS: $\hat{\beta}=0.11, z=0.19, p=.852$ for inflection, $\hat{\beta}=0.25, z=0.37, p=.711$ for stem; $\mathrm{SA}: \hat{\beta}=-0.07, z=-0.12, p=.903$ for inflection, $\hat{\beta}=0.67, z=1.01, p=.315$ for stem). However, spelling of derivations was less accurate in adjectives than in nouns across groups $(\hat{\beta}=2.05, z=3.99, p<.001$ for $\mathrm{CA}, \hat{\beta}=1.68, z=3.76, p<.001$ for DYS, $\hat{\beta}=$ $1.47, z=3.18, p=.002$ for SA). For children with dyslexia the difference between the spelling of derivations and each of the other morphological components was greater for adjectives than for nouns (part of speech by morphological component interaction: $\hat{\beta}=$ $-1.38, z=-2.12, p=.034$ for derivation-stem; $\hat{\beta}=-1.54, z=-2.22, p=.027$ for 
derivation-inflection). For SA control children this was only true for the difference between spelling of derivations and inflections $(\hat{\beta}=-1.63, z=-2.39, p=.017 ; \hat{\beta}=$ $-0.75, z=-1.13, p=.258$ for derivation-stem). For CA control children the differences were the same across part of speech $(\hat{\beta}=-0.26, z=-0.33, p=.742$ for derivation-stem; $\hat{\beta}=-1.63, z=-1.74, p=.082$ for derivation-inflection).

Thus, it seems that all participants and especially children with dyslexia had greater difficulty with the spelling of derivational suffixes, especially of adjectives, than with the spelling of inflectional suffixes of both nouns and adjectives.

\section{Nouns and verbs}

Table 1 (bottom) and Figure 1 (right) show the performance of the 3 groups on the spelling of nouns and verbs. The comparison between the two control groups showed that their spelling performance differed significantly across part of speech and morphological component, with younger control children performing significantly less accurately than older control children (noun: $\hat{\beta}=-1.41, z=-3.18, p=.002$ for stem, $\hat{\beta}=$ $-2.89, z=-2.51, p=.012$ for inflection; verbs: $\hat{\beta}=-1.46, z=-4.44, p<.001$ for stem, $\hat{\beta}$ $=-.95, z=-2.39, p=.017$ for inflection).

Similarly children with dyslexia performed significantly worse than CA control children in spelling both morphological components of both nouns and verbs (nouns: $\hat{\beta}=$ $-2.01, z=-4.3, p<.001$ for stem, $\hat{\beta}=-1.48, z=-2.03, p=.043$ for inflection; verbs: $\hat{\beta}$ $=-2.04, z=-4.97, p<.001$ for stem, $\hat{\beta}=-2.04, z=-4.37, p<.001$ for inflection).

The comparison between children with dyslexia and younger typically developing spellers produced significant group differences in the spelling of noun and verb 
inflections (nouns: $\hat{\beta}=-1.20, z=-1.99, p=.047$, verbs: $\hat{\beta}=.68, z=2.10, p=.036$ ), whereby children with dyslexia spelled significantly more accurately the noun inflections, but were significantly worse than SA controls in the spelling of verb inflections. The group comparisons in the spelling of noun and verb stems were not significantly different (nouns: $\hat{\beta}=0.59, z=1.54, p=.125$, verbs: $\hat{\beta}=.53, z=1.74, p=$ $.082)$.

The difference between morphological components (stem vs. inflection) was significant only in the case of nouns, across groups, in which the inflections were more accurately spelled than stems (nouns: $\hat{\beta}=-7.46, z=-2.46, p=.014$ for $\mathrm{CA}, \hat{\beta}=-4.90, z$ $=-5.87, p<.001$ for DYS, $\hat{\beta}=-3.01, z=-6.33, p<.001$ for SA; verbs: $\hat{\beta}=-1.58, z=$ $-1.21, p=.228$ for CA, $\hat{\beta}=-0.87, z=-1.30, p=.193$ for DYS, $\hat{\beta}=-0.88, z=-1.48, p$ $=.138$ for SA). This difference was significantly greater for the children with dyslexia than for SA control children (group by morphological component, for nouns: $\hat{\beta}=-1.77, z$ $=-2.86, p=.004)$.

Comparing the two parts of speech, there was no significant difference between nouns and verbs in spelling of stems by any group $(\hat{\beta}=.60, z=.86, p=.389$ for CA, $\hat{\beta}=$ $0.81, z=1.48, p=.138$ for DYS, $\hat{\beta}=.72, z=1.13, p=.260$ for SA). However, spelling of inflections was significantly less accurate in verbs than in nouns across groups $(\hat{\beta}=$ $-6.18, z=-2.00, p=.046$ for CA, $\hat{\beta}=-2.84, z=-3.70, p<.001$ for DYS, $\hat{\beta}=-1.75, z=$ $-3.13, p=.002$ for SA).

\section{Qualitative error analysis}

A qualitative analysis of the spelling errors made by each group was undertaken 
to investigate the most common alternative vowel spellings (see Table 2 for the percentages of spelling errors in suffix vowels and the most common alternative spellings). Qualitative analysis focused on vowels /i/, /e/, and /o/ in derivational suffixes, as these were least consistently spelled. The majority of errors occurred in less common spelling patterns ('v'/i/, 'ol'/i/, ' $\omega$ '/o/, ' $\alpha \iota^{\prime} / \mathrm{e} /$, and ' $\left.\varepsilon \imath^{\prime} / \mathrm{i} /\right)$, with fewest errors in the most common graphemes (' $\mathrm{l}$ '/i/, ' $\eta$ '/i/ and 'o'/o/), across groups and parts of speech. Moreover, less common vowel graphemes were substituted with the most common graphemes. For instance, in the case of the phoneme /o/ children made more errors in suffixes spelled with ' $\omega$ ' and used the most common alternative spelling 'o'. Their spelling of the 'o' was approximately $90 \%$ accurate. Similarly, in the case of /i/ children were less accurate when it was represented by less common spellings (e.g., 'v' and the digraphs 'ol' \& ' $\varepsilon \imath^{\prime}$ ') and all children used the most common alternative spelling patterns instead (i.e., ' $\eta$ ' and ' $~ '$ '). However, same-age typically developing children often misspelled a less common grapheme (i.e., the digraph 'or') with another less common grapheme (i.e., the digraph ' $\varepsilon \iota^{\prime}$ ), a pattern rarely observed in children with dyslexia.

The qualitative analysis revealed another interesting pattern: unlike children with dyslexia and younger typical spellers, same-age typically developing children were less accurate in representing the common spelling " $\varepsilon$ " than the less common spelling " $\alpha$ ". This finding indicates that these children have adopted less common spelling representations (e.g., the digraph ' $\alpha \iota^{\prime}$ ) in their repertoire, and are now in a stage of overgeneralizing them, in contrast to children with dyslexia who seem to have difficulties in acquiring such spelling patterns; this overgeneralization results in the decreasing probability of writing more common spelling patterns correctly (Bryant et al., 1999). 


\section{Discussion}

The comparison between the performance of children with dyslexia and chronological-age and spelling-age control children on the grammatical spelling measures revealed effects of group, part of speech, and morphological components of words.

Of particular interest is the finding that, in spelling both adjectives and nouns, all three groups made most spelling errors on the vowels in derivational suffixes than in other morphological components. Inflectional suffixes and (to a lesser degree) stems proved relatively easier. This finding is consistent with Sterling (1983) who showed that twelve-year-olds do not appear to analyze the morphological components of derived words, such as 'closely'. Fischer and colleagues (1985) found that even some adult spellers are unable to incorporate complex derivational relations (for example, the relation between 'courage' and 'courageous').

The younger, spelling-age controls, made significantly more spelling errors in the vowels of derivational suffixes than the chronological-age control children. It seems that there is a developmental progression of morphological spelling skills (Larkin and Snowling, 2008; Read, 1986; Titos, Defior, Alegría, \& Martos, 2003; Treiman, 1993; Treiman, Cassar, \& Zukowski, 1994). Children's sensitivity to derivational morphology and the ability to incorporate this kind of knowledge into spelling is a growing process that develops later than children's sensitivity to inflectional morphology. This finding is in agreement with Protopapas et al. (in press), who showed that derivational suffixes challenge Greek children's spelling. It is also in partial agreement with Jiménez et al. (2008), who found a developmental delay in the acquisition of Spanish regular spelling, 
under the assumption that derivational suffixes represent a challenge of learning systematic patterns within the orthographic system, rather than word-specific knowledge. Henderson (1985) showed that the use of derivational morphology in children's spelling does not take off until the third grade of primary school. Our finding is also consistent with the late emergence of awareness of derivational morphology, as opposed to awareness of inflectional morphology that emerges earlier (Carlisle, 2000; Diakogiorgi et al., 2005; Kuo \& Anderson, 2006).

Children with dyslexia in our sample spelled the morphological components of adjectives and nouns less accurately than typically developing peers. However, their spelling performance was similar to younger spelling-level-matched control children. Our data is consistent with a spelling delay hypothesis, rather than a spelling deviance hypothesis, and in agreement with Protopapas et al. (in press) for Greek, Jiménez et al. (2008) for Spanish, and Abu-Rabia and Taha (2004) for Arabic. In English, Bourassa et al. (2006) also found no differences between the spellings produced by children with dyslexia and younger typical spellers. They argued that the absence of such differences between the two groups signified a delay in their spelling development. Friend and Olson (2008) compared 77 disabled spellers to younger typical spellers on phonological and graphotactic spelling accuracy. They found significant but small group differences only in the phonological accuracy measure, and not on the graphotactic accuracy measure.

The poor performance of children with dyslexia compared to typically developing peers in the spelling of derivational suffixes of both parts of speech (adjective, noun) could be partly understood in terms of the linguistic properties of derivational suffixes in Greek. Derivational morphemes are systematic, as they are specific and have a fixed 
position following a lexical root, but they hold a middle position in words and their spellings are arbitrary as they do not conform to general spelling rules. According to Peters (1997), in English, grammatical morphemes within words tend to be acquired from the outside in, with inner slots being left empty at first, and may be filled at a later stage; as a result, morphemes that are situated in the inner recesses of a word are difficult to perceive. Evidence from studies in West Greenlandic Eskimo indicated that the first combinations to appear are of stems, which are word-initial, and inflections, which are word-final. Derivational markers, which are word-internal, appear later (Fortescue \& Lennert Olsen, 1992).

On the other hand, it has been shown that, across languages, the acquisition of grammatical morphemes is relatively easy when the morphemes occur frequently, have an easily recognizable form, keep a fixed position relative to an open-class stem, have a specific function, and are easy to segment (Peters, 1997). This seems to be the case for the inflectional suffixes examined in our study. Slobin (1973) suggested that morphemes of final position play a characteristically significant role, as they can be easily segmented and occupy a salient position. Studies in Japanese and Mandarin have showed that sentence-final particles are produced early (Erbaugh, 1992; Tardif, 1994). In Hebrew, even children with specific language impairments seem to have few difficulties with inflections, which are clause-final and stressed or lengthened (Dromi, Leonard \& Shteiman, 1993).

Research on the influence of linguistic characteristics of shallow orthographies on readers' word recognition skills has pointed out the role of the inflectional suffix in word reading. Chitiri and Willows (1994) assessed seventy-two English-speaking and sixty- 
five Greek-speaking students (age range 15-17 years) on a letter cancellation task, in which children had to cross out every instance of a certain target letter while reading a short text. It was assumed that readers would detect letters that are processed consciously and miss those that are not, reflecting word processing factors. Results indicated that Greek readers were consistently paying more attention to the last syllable, which carried the inflection, in contrast to their English counterparts, who appeared to attend more to the initial parts of the word. Omission patterns revealed that Greek readers missed target letters in inflections less often than letters in the first or second syllable. It could, therefore, be argued that during the reading process children become more familiar with the spelling patterns included in inflections and increase their orthographic awareness (Georgiou, Parrila, \& Papadopoulos, 2008). In addition, their spellings conform to grammatical spelling rules. As a result, children's spelling skills that are underpinned by inflectional morphology develop in a more efficient way. Therefore the different linguistic characteristics of derivational morphemes as opposed to those of inflections may be related to the spelling problems exhibited by the children of the present sample.

With respect to different parts of speech, the analysis of spelling adjective-noun pairs also revealed an advantage for nouns over adjectives. Specifically, the derivational suffixes of nouns were spelled more accurately than those of adjectives. This difference could be attributed to differences in word familiarity (frequency), since the nouns (log count $M=2.10, S D=1.05)$ were significantly more frequent than adjectives $(M=1.35$, $S D=1.42, t(54)=2.24, p<.05)$. This finding cannot be explained in terms of the teaching instruction since, according to the Greek curriculum, the explicit teaching of derivational suffixes does not favour nouns compared to adjectives. 
The comparison between the performance of children with dyslexia and typically developing children on spelling noun-verb sentences confirmed the results of the adjective-noun measure, with inflectional suffixes posing fewer spelling difficulties to children than stems. There was no significant difference in the spelling of verb stems compared to noun stems, but noun inflections were spelled more accurately than verb inflections. It seems that Greek children use their knowledge of inflectional morphology more effectively for noun inflections than for verb inflections, whereas Spanish-speaking children seem to do the opposite (Titos et al., 2003). This finding, along with the significantly poorer performance of children with dyslexia compared to younger typically developing spellers, could be understood in terms of the morphological properties of Greek verbs. As mentioned in the introduction, Greek verbs are inflected for person, number, tense, voice, and aspect and have a considerably greater variety of different forms than Greek nouns (Holton et al., 2002), which are inflected only for gender, case and number. Apparently, children with dyslexia have not altogether grasped the morphological spelling rules of the complex Greek verb morphology, and in consequence lack the ability to apply this knowledge to the spelling of verb suffixes. We believe that this finding qualifies the developmental lag hypothesis discussed above, because we expect the developmental delays to be largest in verb inflections, considering the variability and complexity of this part of speech.

The qualitative analysis of children's spelling errors in derivational suffixes allowed us to examine the alternative spellings that children use and the frequency with which these occur. Children of all three groups misspelled the vowel phonemes that were represented by the less common graphemes (with the exception of the spelling of the 
common grapheme ' $\varepsilon$ ' by the CA group), using the most common ones instead. These results are in line with Barry and Seymour's study (1988) which revealed a substantial sound-to-spelling-contingency effect; that is, children produced more high-contingency (common) spelling patterns of vowels than low-contingency (rare) spellings.

Evidence from Portuguese (Nunes Carraher, 1985, \& Nunes, 1992, cited in Bryant, Nunes, \& Aidinis, 1999) and Greek (Bryant et al., 1999) suggests that there is a developmental sequence in the use of alternative spelling patterns. At first children show a distinct preference for one spelling choice, but as they advance in years and reading experience there is an increase in the use of alternative spellings. Our data provide support for those findings. For example, the chronological-age control group used the same proportion of common and less common spelling patterns when they misspelled the less common digraph 'ot'. Another characteristic example is the case of the less common digraph ' $\alpha$ ' ' which was used by chronological-age controls more accurately than the more common spelling ' $\varepsilon$ ' to represent the phoneme /e/. The study by Bryant et al. (1999) revealed a similar pattern. Children who had started to adopt the ' $\omega$ ' spelling, as well as the ' $\mathrm{o}$ ' spelling (both represent the phoneme /o/) were correct in only ninety-three per cent of the words ending in the common 'o' spelling. The authors argued that the probability of writing the words ending in ' $\omega$ ' correctly increased, but at the same time the probability of spelling the 'o' correctly decreased. Our findings are also in line with those of Egan et al. (2011), who showed that children with dyslexia made fewer overgeneralisations of the -ed ending than younger and same-age typically developing children.

Overall the data presented in this study underscore the importance of 
morphological information in the spelling of word suffixes by both typically developing young individuals and children with dyslexia. Knowledge of inflectional morphology in Greek is a necessary requirement for the correct spelling of word endings. Our data are consistent with the hypothesis that children of ten to thirteen years of age have internalised and generalised the morpho-grammatical information necessary for spelling the endings of nouns, adjectives and verbs. Children with dyslexia appear to have weaknesses in applying morphological information in the spelling of word endings when compared to their typically developing peers. However, they generally perform at the same level as the younger spelling-level-matched control children. Moreover children with dyslexia made similar substitutions to those of younger typically developing spellers, preferring the most common grapheme. This suggests that children with dyslexia process written material to extract coarse statistics, but, like younger SA children, do not make finer distinctions amongst spelling patterns. Therefore an interpretation of a spelling delay, rather than deviance, is consistent with our data.

The present study has established the substantial importance of derivational morphology in word spelling. The derivational suffix is the morphological component in which most spelling errors were observed for both children with dyslexia and typically developing spellers. It is therefore suggested that teaching of derivational morphology in Greek schools is imperative. A systematic and explicit teaching approach to derivational morphology and the spelling of derivational suffixes may be particularly effective for young spellers and especially those who suffer from developmental dyslexia. It is also suggested that educators working with children with dyslexia should raise these children's awareness of the existence of different spelling patterns for the representation 
of vowels. Moreover, the present findings have pointed out a specific area of intervention: the case of the verb in Greek should be a major part of remediation programmes for children with dyslexia. The causal role and the effectiveness of explicit teaching of derivational morphology in spelling could be further tested in intervention studies. 


\section{References}

Abu-Rabia, S., \& Taha, H. (2004). Reading and spelling error analysis of native Arabic dyslexic readers. Reading and Writing: An Interdisciplinary Journal, 17, 651-689.

Aidinis, A., \& Nunes, T. (2001). The role of different levels of phonological awareness in the development of reading and spelling in Greek. Reading and Writing: An Interdisciplinary Journal, 14, 145-177.

Alegria, J., \& Mousty, P. (1996). The development of spelling procedures in Frenchspeaking, normal and reading-disabled children: Effects of frequency and lexicality. Journal of Experimental Child Psychology, 63, 12-338.

Anglin, J. M. (1993). Vocabulary development: A morphological analysis. Monographs of the Society for Research in Child Development, 58 (Serial \#238).

Baayen, R. (2008). Analyzing linguistic data: A practical introduction to statistics using $R$. Cambridge University Press.

Barr, D. J., Levy, R., Scheepers, C., \& Tily, H. J. (2013). Random effects structure for confirmatory hypothesis testing: Keep it maximal. Journal of Memory and Language, 68, 255-278.

Bates, D., Maechler, M., \& Bolker, B. (2012). lme4: Linear mixed-effects models using S4 classes. $\mathrm{R}$ package version 0.999999-0. http://CRAN.Rproject.org/package=lme4.Barry, C., \& Seymour, P. H. K. (1988). Lexical priming and sound-to-spelling contingency effects in nonword spelling. The Quarterly Journal of Experimental Psychology, 40A, 5-40.

Bradley, L., \& Bryant, P. (1985). Rhyme and reason in reading and spelling. Ann Arbor: University of Michigan Press. 
Bruck, M., \& Treiman, R. (1990). Phonological awareness and spelling in normal children and dyslexics - the case of initial consonant clusters. Journal of Experimental Child Psychology, 50, 156-178.

Bryant, P., Nunes, T., \& Bindman, M. (1997). Backward readers' awareness of language: strengths and weaknesses. European Journal of Psychology of Education, 12, 357372.

Bryant, P., Nunes, T., \& Aidinis, A. (1999). Different morphemes, same spelling problems: cross-linguistic developmental studies. In M. Harris \& G. Hatano (Eds.), Learning to read and write. A cross-linguistic perspective. (pp. 112-133). Cambridge University Press.

Bourassa, D. C., Treiman, R., \& Kessler, B. (2006). Use of morphology in spelling by children with dyslexia and typically developing children. Memory \& Cognition, 34, 703-714.

Bourassa, D. C., Treiman, R. (2008). Morphological constancy in spelling: A comparison of children with dyslexia and typically developing children. Dyslexia, 14, 155-169.

Caravolas, M., Hulme, C., \& Snowling, M. J. (2001). The Foundations of spelling ability: Evidence from a 3-year longitudinal study. Journal of Memory and Language, 45, 751-774.

Caravolas, M. (2004). Spelling development in alphabetic writing systems: A crosslinguistic perspective. European Psychologist, 9, 3-14.

Cardoso-Martins, C., \& Pennington, B. F. (2004). The relationship between phoneme awareness and rapid serial naming skills and literacy acquisition: The role of developmental period and reading ability. Scientific Studies of Reading, 8, 27-52. 
Carlisle, F. J. (1988). Knowledge of derivational morphology and spelling ability in fourth, sixth and eighth graders. Applied Psycholinguistics, 9, 247-266.

Casalis, S., Deacon, S. H., \& Pacton, S. (2011). How specific is the connection between morphological awareness and spelling? A study of French children. Applied Psycholinguistics, 32, 499-511.

Cassar, M., Treiman, R., Moats, L., Pollo, T. C., \& Kessler, B. (2005). How do the spellings of children with dyslexia compare with those of nondyslexic children? Reading and Writing, 18, 27-49.

Georgas, D. D., Paraskevopoulos, I. N., Besevegis, I. G. \& Giannitsas N. D. (1997).

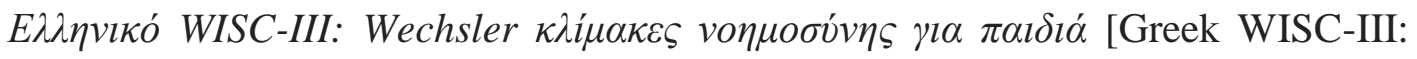
Wechsler intelligence scales for children]. Athens: Ellinika Grammata.

Chitiri, H. F., \& Willows, D. M. (1994). Word recognition in two languages and orthographies: English and Greek. Memory \& Cognition, 22, 313-325.

Deacon, S. H., \& Bryant, P. E. (2005). What young children do and do not know about the spelling of inflections and derivations. Developmental Science, 8, 583-594.

Deacon, S. H., \& Bryant, P. E. (2006). Getting to the root: Young writers' sensitivity to the role of root morphemes in the spelling of inflected and derived words. Journal of Child Language, 33, 401-417.

Defior, S., Alegría, J., Titos, R., \& Martos, F. (2008). Using morphology when spelling in a shallow orthographic system: The case of Spanish. Cognitive Development, 23, 204-215.

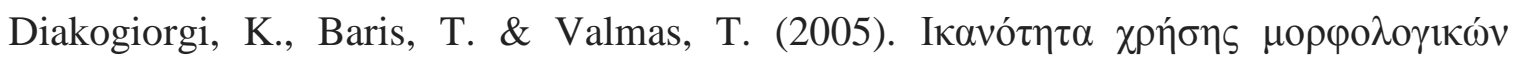

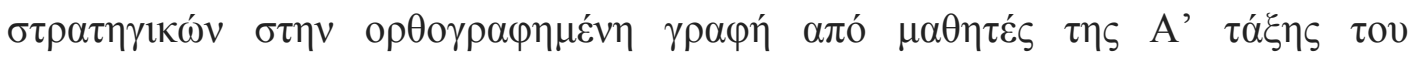


$\delta \eta \mu о \tau \varkappa \kappa o v ́$ [The ability of using morphological strategies in spelling by firstgraders]. Psychologia, 12, 568-586.

Dixon, P. (2008). Models of accuracy in repeated-measures designs. Journal of Memory and Language, 59, 447- 456.

Dromi, E., Leonard, L. B., \& Shteiman, M. (1994). The grammatical morphology of Hebrew-speaking children with specific language impairment: Some competing hypotheses. Journal of Speech and Hearing Research. 36, 760-771.

Egan, J., \& Tainturier. M. J. (2011). Cortex, 47, 1179-1196.

Erbaugh, M. S. (1992). The acquisition of Mandarin. In D. I. Slobin (Ed.), The crosslinguistic study of language acquisition, Vol. 3. Hillsdale, NJ: Lawrence Erlbaum.

Fischer, F. W., Shankweiler, D., \& Liberman, I.Y. (1985). Spelling proficiency and sensitivity to word structure. Journal of Memory and Language, 24, 423-441.

Fortescue, M., \& Lennert Olsen, L. (1992). The acquisition of West Greenlandic. In D. I. Slobin (Ed.), The crosslinguistic study of language acquisition, Vol. 3. Hillsdale, NJ: Lawrence Erlbaum.

Friend, A., \& Olson, R. K (2008). Phonological spelling and reading deficits in children with spelling disabilities. Scientific Studies of Reading, 12, 90-105.

Furnes, B., \& Samuelsson, S. (2010). Predicting reading and spelling difficulties in transparent and opaque orthographies: A comparison between Scandinavian and US/Australian children. Dyslexia, 16, 119-142.

Hatzigeorgiu, N., Gavrilidou, M., Piperidis, S., Carayannis, G., Papakostopoulou, A., Spiliotopoulou, A., et al. (2000, 31 May-2 June). Design and implementation of the 
online ILSP corpus. In Proceedings of the second international conference of language resources and evaluation (LREC) (Vol. 3, pp. 1737-1740). Athens, Greece.

Henderson, E. (1985). Teaching Spelling. Boston: Houghton Mifflin.

Holton, D., Mackridge, P., \& Philippaki-Warburton, I. (2004). Greek: A comprehensive grammar of the modern language. London: Routledge.

Jaeger, T. F. (2008). Categorical data analysis: Away from ANOVAs (transformation or not) and towards logit mixed models. Journal of Memory and Language, 59, 434446.

Jarvella, R. J., Job, R., Sandstrom, G., \& Schreuder, R. (1987). Morphological constraints on word recognition. In A. Allport, D. G. Mackey, W. Prinz., \& G. Scheerer (Eds.), Language perception and production (pp. 245-262). London: Academic Press.

Jiménez, J. E., O'Shanahan, I., de la Luz Tabraue, M., Artiles, C., Muñetón, M., Guzmán, R., Naranjo, F., Rojas, E. P. (2008). Evolución de la escritura de palabras de ortografía arbitraria en lengua Española [Spelling development in the Spanish language]. Psicothema, 20, 786-794.

Kuo, L. J., \& Anderson, R. C. (2006). Morphological awareness and learning to read: A cross-language perspective. Educational Psychologist, 41, 161-180.

Landerl, K., \& Reitsma, P. (2005). Phonological and morphological consistency in the acquisition of vowel duration in Dutch and German. Journal of Experimental Child Psychology, 92, 741-769.

Landerl, K., \& Wimmer, H. (2008). Development of word reading fluency and spelling in a consistent orthography: An 8-year follow-up. Journal of Educational Psychology, 
$100,150-161$.

Larkin, R. F., \& Snowling M. J. (2008). Morphological spelling development. Reading \& Writing Quarterly, 24, 363-376.

Levin, I., Ravid, D. \& Rapaport, S. (2001). Morphology and spelling among Hebrewspeaking children: from kindergarden to first grade. Journal of Child Language, 28, $322-344$.

Maxwell, S. E., \& Delaney, H. D. (1990). Designing experiments and analyzing data: A model comparison perspective. Belmont, CA: Wadsworth.

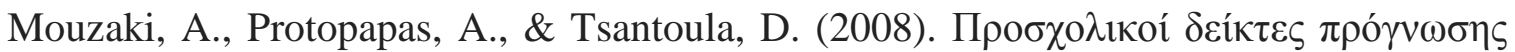

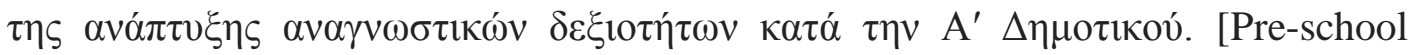
predictors of the development of reading skills in first grade]. Epistimes tis Agogis, $1,71-88$.

Nikolopoulos, D., Goulandris, N., Hulme, C., \& Snowling, M. J. (2006). The cognitive bases of learning to read and spell in Greek: Evidence from a longitudinal study. Journal of Experimental Child Psychology, 94, 1-17.

Nikolopoulos, D., Goulandris, N., \& Snowling, M. J. (2003). Developmental dyslexia in Greek. In N. Goulandris, Dyslexia in Different Languages: Cross-linguistic Comparisons, 53-67, London: Whurr.

Nunes Carraher, T. (1985). Explorações sobre o desenvolvimento da competência em ortografia em português [Exploring the development of spelling competence in Portuguese]. Psicologia: Teoria e Pesquisa, 1, 269-85.

Nunes, T. (1992). Leitura e escrita: Processos e desenvolvimento [Processes and development in reading and spelling]. In E. S. de Alencar (Ed.), Novas 
contribuições da psicologia aos processos de ensino e aprendizagem [New contributions from psychology to teaching and learning] (pp. 13-50). Sao Paulo: Cortez Editora.

Nunes, T., Bryant, P. E., \& Bindman, M. (1997). Morphological spelling strategies: developmental stages and processes. Developmental Psychology, 33, 637-49.

Nunes, T., Bryant. P., \& Nunes, T. (1997). Learning to spell regular and irregular verbs. Reading and Writing: An Interdisciplinary Journal, 9, 427-449.

Pacton, S., \& Deacon, S. H. (2008). The timing and mechanisms of children's use of morphological information in spelling: A review of evidence from English and French. Cognitive Development, 23, 339-359.

Pacton, S., Fayol, M., \& Perruchet, P. (2005). Children's implicit learning of graphotactic and morphological regularities. Child Development, 76, 324-339.

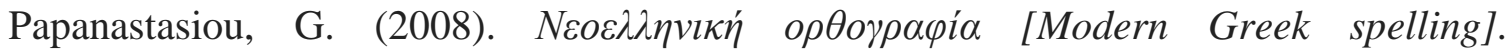
Thessaloniki: Modern Greek Studies Institute.

Peters, A. M. (1997). Language typology, prosody, and the acquisition of grammatical morphemes. In D. I. Slobin. The cross-linguistic study of language acquisition, Vol. 5 (pp. 135-197). Hillsdale, NJ: Erlbaum.

Protopapas, A., Fakou, A., Drakopoulou, S., Skaloumbakas, C., \& Mouzaki, A. (in press). What do spelling errors tell us? Classification and analysis of errors made by Greek schoolchildren with and without dyslexia. Reading \& Writing: An Interdisciplinary Journal. doi:10.1007/s11145-012-9378-3

Protopapas, A., \& Vlahou, E. L. (2009). A comparative quantitative analysis of Greek orthographic transparency. Behavior Research Methods, 41, 991-1008. 
R Core Team (2012). R: A language and environment for statistical computing. R Foundation for Statistical Computing, Vienna, Austria. http://www.R-project.org/.

Ralli, A. (2003). Morphology in Greek linguistics. The state of the Art. Journal of Greek Linguistics, 4, 77-129.

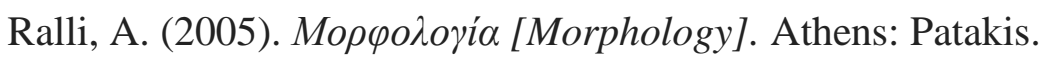

Read, C. (1986). Children's creative spelling. London: Routledge and Kegan Paul.

Sénéchal, M., Basque, M., \& Leclaire, T. (2006). Morphological knowledge as revealed in children's spelling accuracy and reports of spelling strategies. Journal of Experimental Child Psychology, 95, 231-254.

Slobin, D. I. (1973). Cognitive prerequisites for the development of grammar. In C. A. Ferguson \& D. I. Slobin (Eds.), Studies of child language development (pp. 175208). New York: Holt, Rinehart \& Winston.

Sterling, C. M. (1983). Spelling errors in context. British Journal of Psychology, 74, 353364.

Tardif, T. Z. (1994). Adult-to-child speech and language acquisition in Mandarin Chinese. Dissertation Abstracts International: Section B: The Sciences and Engineering. 55, 615.

Titos, R., Defior, S., Alegria, J., \& Martos, F. (2003). The use of morphological resources in Spanish orthography. In R. M. Joshi, C. K. Leong \& B. L. J. Kaczarek (Eds.), Literacy Acquisition: The Role of Phonology, Morphology and Orthography. Amsterdam: IOS Press.

Torgesen, J. K., Wagner, R. K., \& Rashotte, C. A. (1999). Test of word reading efficiency. Austin, TX: Pro-Ed. 
Totereau, C., Thevenin, M. G., \& Fayol, M. (1997). The development of the understanding of number morphology in written French. In C. Perfetti, M. Fayol \& L. Rieben (Eds.), Learning to Spell (pp. 97-114). Hillsdale, NJ: Erlbaum.

Treiman, R. (1993). Beginning to spell. New York: Oxford University Press.

Treiman, R., Cassar, M., \& Zukowski, A. (1994). What types of linguistic information do children use in spelling? The case of flaps. Child Development, 65, 1318-1337.

Wagner, R. (1988). Causal relations between the development of phonological processing abilities and the acquisition of reading skills: A meta-analysis. Merrill-Palmer Quarterly, 34, 261-279.

Wagner, R. K., \& Torgesen, J. K. (1987). The nature of phonological processing and its causal role in the acquisition of reading skills. Psychological Bulletin, 101, 192212.

Wagner, R. K., Torgesen, J. K., Laughan, P., Simmons, K., \& Rashotte, C. A. (1993). The development of young readers' phonological processing abilities. Journal of Educational Psychology, 85, 1-20. 
Table 1

Performance of each group on each task (\% correct)

\begin{tabular}{lccc}
\hline & $\begin{array}{c}\text { Chronological- } \\
\text { Age Controls }\end{array}$ & $\begin{array}{c}\text { Children } \\
\text { with Dyslexia }\end{array}$ & $\begin{array}{c}\text { Spelling-Age } \\
\text { Controls }\end{array}$ \\
\hline Adjectives and nouns & $90(7)$ & $81(7)$ & $79(10)$ \\
Adjectival stems & $79-100$ & $71-96$ & $57-92$ \\
Min-max & $94(7)$ & $82(12)$ & $83(10)$ \\
Noun stems & $79-100$ & $50-100$ & $61-100$ \\
Min-max & $74(16)$ & $47(15)$ & $56(14)$ \\
Adjective derivational suffixes & $40-100$ & $20-84$ & $28-88$ \\
Min-max & $90(10)$ & $73(14)$ & $77(13)$ \\
Noun derivational suffixes & $75-100$ & $46-96$ & $54-100$ \\
Min-max & $97(4)$ & $89(10)$ & $91(7)$ \\
Adjective inflectional suffixes & $86-100$ & $64-100$ & $75-100$ \\
Min-max & $98(3)$ & $91(6)$ & $91(7)$ \\
Noun inflectional suffixes & $89-100$ & $71-100$ & $75-100$ \\
Min-max & & & \\
\hline Verbs and nouns & $79(18)$ & $49(19)$ & $59(17)$ \\
Noun stems & $44-100$ & $22-89$ & $28-100$ \\
Min-max & $84(10)$ & $64(14)$ & $70(10)$ \\
Verb stems & $61-94$ & $39-89$ & $56-89$ \\
Min-max & $99(3)$ & $95(5)$ & $95(6)$ \\
Noun inflectional suffixes & $89-100$ & $83-100$ & $78-100$ \\
Min-max & $87(9)$ & $74(12)$ & $83(8)$ \\
Verb inflectional suffixes & $67-100$ & $56-100$ & $67-100$ \\
Min-max & & & \\
\hline
\end{tabular}

Note. Number of participants $=20$ in each group; Number of noun and adjective stems \& inflectional suffixes $=28$ in each part of speech; Number of noun derivational suffixes $=22$; Number of adjectival derivational suffixes $=23$; For verbs and nouns, number of items $=18$ in each part of speech; standard deviations are in parentheses; percentages were rounded to the nearest integer. 
Table 2

Percentages of spelling errors and common substitutions on the graphemes of adjective and noun derivational suffixes that represent the phonemes /e/, /o/ and /i/.

\begin{tabular}{|c|c|c|c|}
\hline $\begin{array}{l}\text { grapheme } \\
\text {-phoneme }\end{array}$ & Spelling-age Controls & $\begin{array}{l}\text { Chronological-age } \\
\text { Controls }\end{array}$ & Children with Dyslexia \\
\hline${ }^{\prime} \mathbf{0} ' / \mathbf{0} /$ & $12(67 ‘ \omega ’)$ & $4(100$ ‘ $\omega ’)$ & $8(88$ ‘ $\omega ’)$ \\
\hline${ }^{\prime} \omega ' / \mathbf{0} /$ & 41 (100 ‘o’) & 35 (100 ‘o’) & 61 (90 ‘o’) \\
\hline ' $\mathbf{\varepsilon}$ '/e/ & $19\left(84\right.$ ' $\left.\alpha \imath^{\prime}\right)$ & $21\left(95\right.$ ' $\left.\alpha \imath^{\prime}\right)$ & $30\left(83\right.$ ' $\left.\alpha \imath^{\prime}\right)$ \\
\hline ' $\boldsymbol{\alpha u} ' / \mathbf{e} /$ & 38 (93 ' $\varepsilon$ ') & $13(100$ ‘ $\varepsilon$ ') & $63(96$ ‘ $\varepsilon ’)$ \\
\hline \multirow[t]{2}{*}{$' v ' / \mathbf{i} /$} & 49 & 24 & 59 \\
\hline & 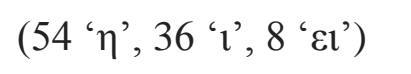 & (53 ‘'’, 47 ‘ $\eta ’)$ & $(66$ ' $\eta$ ’, 34 '‘’) \\
\hline \multirow[t]{2}{*}{ 'ol' /i/ } & 49 & 24 & 49 \\
\hline & $\begin{array}{l}\left(59 \text { ' ‘', } 28 \text { ' } \varepsilon \iota^{\prime}, 8 \text { ' } \eta \text { ’, } 3\right. \\
\text { 'v') }\end{array}$ & $\begin{array}{l}\left(42 \text { ' } \imath \text { ', } 42 \text { ' } \varepsilon \imath^{\prime}, 11 \text { ' } \eta \text { ’, } 5\right. \\
\text { 'v') }\end{array}$ & 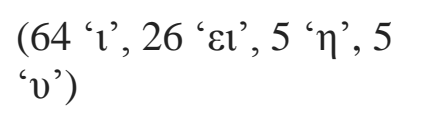 \\
\hline \multirow[t]{2}{*}{ ' $\varepsilon \mathbf{l} ' / \mathbf{i} /$} & 49 & 21 & 52 \\
\hline & $\begin{array}{l}(84 \text { ' } \imath ’, 8 \text { 'oı', } 6 \text { ' } \eta \text { ', } 2 \\
\text { 'v') }\end{array}$ & 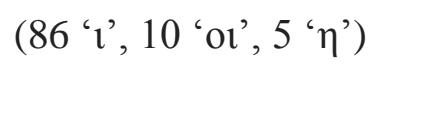 & 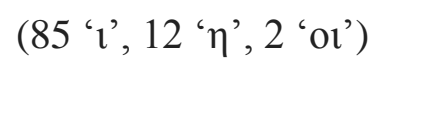 \\
\hline \multirow[t]{2}{*}{$' \eta ' / \mathbf{i} /$} & 21 & 14 & 34 \\
\hline & (84 ‘'’, 13 'ol’, 3 ‘v’) & (88 ‘ $\imath^{\prime}, 8$ 'ol’, 4 'v’) & $\begin{array}{l}(81 \text { ' }\urcorner \text { ', } 8 \text { 'ot', } 5 \text { 'v', } 3 \\
\text { 'et') }\end{array}$ \\
\hline \multirow[t]{2}{*}{ ' $\mathbf{l}$ '/i// } & 23 & 11 & 22 \\
\hline & $\begin{array}{l}(65 \text { ' } \eta \text { ', } 9 \text { ‘ol', } 9 \text { ‘v', } 5 \\
\text { 'cl') }\end{array}$ & $\begin{array}{l}(79 \text { ' } \eta \text { ', } 7 \text { 'ot', } 7 \text { 'ct', } 5 \\
\text { 'v') }\end{array}$ & $\begin{array}{l}\left(67 \text { ' } \eta \text { ', } 11 \text { 'ot', } 6 \text { ' } \varepsilon \imath^{\prime}, 3\right. \\
\text { 'v') }\end{array}$ \\
\hline
\end{tabular}

Note. Percentages of the most common substitutions in parentheses. Substitutions do not necessarily add up to $100 \%$ due to other kinds of errors (omissions or phonological errors). 


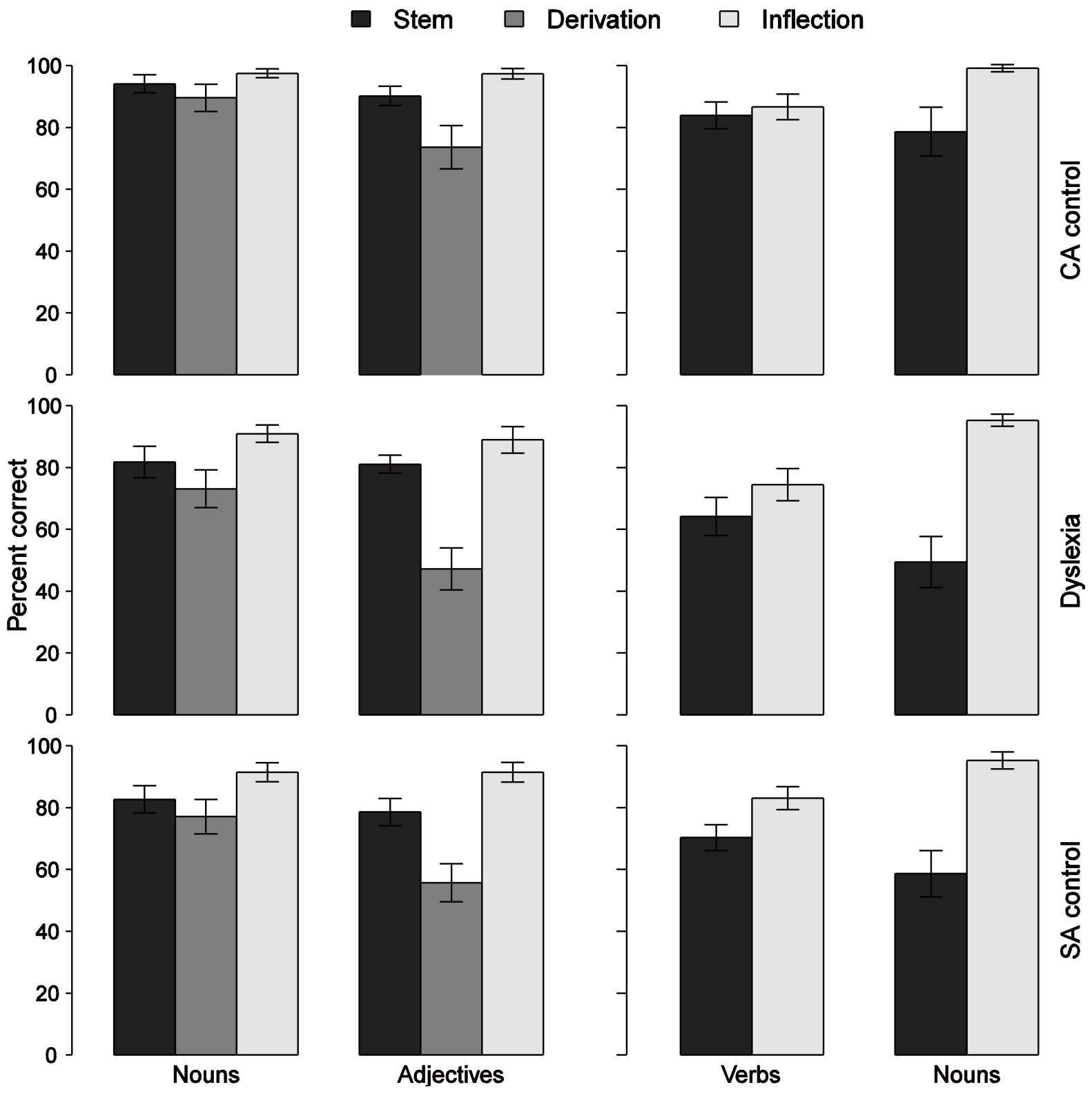

Figure 1. Percent correct spelling for each group and word part. Left, nouns and adjectives (word pair task); Right, verbs and nouns (sentence task). Error bars show standard error. 